\title{
Study on the Reverse Heat Conduction Behavior of Steel
}

\author{
Shi Xiong \\ College of Ocean Science and Engineering, Shanghai Maritime University, Shanghai, China \\ Email: lionxiongshi@163.com
}

How to cite this paper: Xiong, S. (2020) Study on the Reverse Heat Conduction Behavior of Steel. Open Journal of Safety Science and Technology, 10, 24-31. https://doi.org/10.4236/ojsst.2020.101002

Received: March 7, 2020

Accepted: March 28, 2020

Published: March 31, 2020

Copyright ( 2020 by author(s) and Scientific Research Publishing Inc. This work is licensed under the Creative Commons Attribution International License (CC BY 4.0).

http://creativecommons.org/licenses/by/4.0/

\begin{abstract}
This paper analyses the existing literature, and considered the new problems caused by the burning accident of thermal insulation materials attached to the steel structure in recent years. In the process of combustion, thermal insulation materials will drip and melt, producing a large amount of liquid fuel. The combustion of thermal insulation materials attached to steel (diameter longer than $0.2 \mathrm{~m}$ ) can be regarded as large pool fire combustion, and a mathematical model is established to study the reverse thermal conduction behavior of the combustion of combustible materials attached to steel.
\end{abstract}

\section{Keywords}

Steel, Radiant Heat Flux, Semi-Empirical Radiation Model

\section{Introduction}

Nowadays, with the rapid development of urban construction, the demand for various kinds of steel and other resources is also rising. Steel has the advantages of good structural performance, low pollution and convenient construction, so steel structure is widely used in modern building construction, the main material for liquefied gas transportation storage tank is mostly steel. However, due to the relatively low fireproof performance of steel structure itself, and the fact that it is easy to reduce its own stiffness and strength at high temperature, the exposure of steel structure to potential fire source may lead to the occurrence of safety accidents. In order to prevent the steel structure from being exposed to the dangerous source, people would like to add some insulation materials to cover it to prevent the damage of high temperature to the steel structure. In fact, this is only exposed to the source of the steel structure to replace the insulation material. 
On August 17, 2014, the external insulation material of LNG storage tank under construction in changxing shipyard of China shipbuilding group caught fire, which led to new thinking on the fire caused by combustible materials attached to steel structure. In short, the neglected insulation material will also burn under the constant high temperature, and the thermal feedback will be transmitted down to the surface of the steel structure and affect it. Absolutely, it is necessary to test the influence law of thermal feedback on tank structure for the influence of fire caused by the burning of insulation materials attached to the tank outside. To solve these problems, it is necessary to accurately predict the thermal feedback from the flame to the steel. Wang and Zhou [1] [2] et al. proposed a multi-layered cylindrical flame model to predict the radiant heat flow field of pool fire. The solid flame model [3] usually looks at the flame as a cylinder, assuming that the cylinder surface uniformly releases heat with the fixed surface thermal radiation intensity. These are semi-empirical models for predicting the radiant heat feedback from a flame to its surroundings. At present, there is no research on flame-to-steel which under fire radiant heat feedback model.

Based on the analysis of the existing data, a semi-empirical model of radiative heat feedback is proposed to predict the reverse heat conduction behavior of the flame on the steel surface by the flame to the steel surface.

\section{Definition of Combustion of Combustible Materials Attached to Steel}

In the era of highly developed building industry and energy industry, the insulation materials are frequently used. Some studies have been conducted on polyurethane foam materials [4]-[8]. The density of polyurethane foam has a certain influence on the spread of combustion, and the combustion rate varies with the location of the fire. The literature [7] [8] [9] studied the flame height and flame pulsation when FPU burns downward, and found that the predicted value of pool fire theory was consistent with the experimental results. Many common thermal insulation materials, such as polymethyl methacrylate (PMMA), polystyrene foam plastic (XPS), expanded polystyrene (EPS), will appear droplets of molten phenomenon in the process of combustion, which is essentially a narrow as shown in Figure 1, downward flow of pool fire (as shown in Figure 1), rather than the spread of more common down like solid combustion flame [10] [11]. In literature [12] [13], the thermal insulation materials at different inclinations were tested under different ambient air pressures, and it was found that pool fire theory could be used to explain the relationship between combustion rate and air pressure at different inclinations. The general characteristics of pool fire are diffused flame on the flat fuel surface, in which buoyancy is the main mechanism to control transportation. Therefore, when the combustible material attached to steel burns, it can be considered that the combustion reaction similar to pool fire will be formed when the combustible material attached to steel burns. In the pool fire, the dominant heat transfer mechanism is usually 


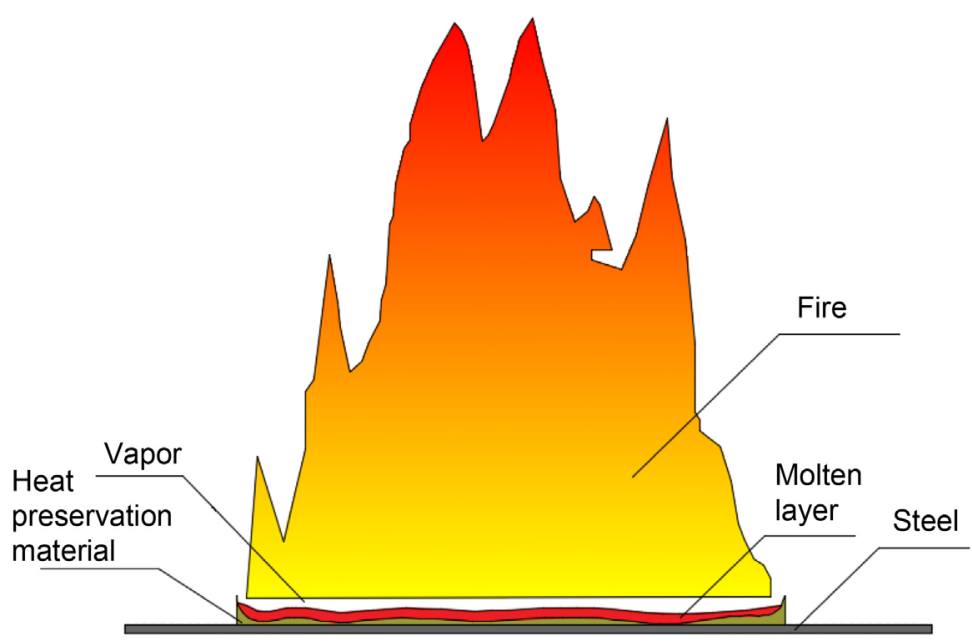

Figure 1. Schematic diagram of thermal insulation material combustion.

related to the size of the pool. Blinov and Khudyakov [14] divided the main modes of heat feedback into three categories: when the pool diameter is less than $0.1 \mathrm{~m}$, the conduction feedback is dominant; when the pool diameter is less than $0.2 \mathrm{~m}$ and longer than $0.1 \mathrm{~m}$, the convection feedback is dominant; when the pool diameter is longer than $0.2 \mathrm{~m}$, the radiation feedback is dominant. Hottel [15] also conducted an in-depth analysis of the flame heat transfer phenomenon related to the combustion of liquid pool fires. In actual fires, it is mainly radiation heat transfer, rather than conduction and convection heat transfer, which are the characteristics of small-scale laboratory fires. Thus it can be seen that the combustion reaction when the combustible material attached to the steel (diameter longer than $0.2 \mathrm{~m}$ ) burns is the pool fire dominated by radiation feedback.

\section{Research on the Model of Flame Radiation}

According to the introduction in the previous section, for the flame of steel attached combustible material (diameter longer than $0.2 \mathrm{~m}$ ), there will be a radiation-dominated thermal feedback to the steel structure. To explore the influence of flame radiation on steel structure, a suitable flame radiation model should be established.

At present, the applicable semi-empirical models for theoretical calculation can be basically divided into two types: point source model and solid flame model. The point-source model is simple to calculate but not accurate enough [16]. In this method, flame radiation is regarded as being emitted from a point source in the flame axis to the target object, thus ignoring the influence of factors such as the width and distance of the flame on the accuracy. The solid flame model [3] usually looks at the flame as a cylinder, assuming that the surface of the cylinder uniformly releases heat with a fixed surface thermal radiation intensity, and the radiant heat feedback received by the target object is calculated by atmospheric transmission coefficient, Angle coefficient and other parameters. 
Compared with the point source model, the solid flame model is more dependent on the surface integral of the flame. Some scholars also discretized the point source model according to the principle of the same flame width and combustion rate, used the optimal number of control points to directly affect the accuracy of calculation, and finally obtained the improved point source method [17]. Although the improved point source method is more accurate than the point source method, it is not as accurate as the solid flame model nor as simple and convenient as the point source method. Zhou et al. [18] established an improved method for predicting the flame radiant heat flow of pool fire by combining the influence of flame pulsation characteristics on the flame radiant heat flow field. Wang and Zhou [1] [2] et al. proposed a multi-layer cylindrical flame model to predict the radiant heat flow field of pool fire. It is assumed that the flame is composed of several small cylindrical flames, which have different surface emission powers. Therefore, the radiant heat flow received by the target from pool fire is the sum of all small cylindrical flames. The model needs to determine the reasonable number of layers and layers. Based on the monte carlo method, shen et al. [19] calculated the radiation feedback from the fire source to the target object by using the mean value of random samples generated by computer simulation, which simplified the calculation process and obtained relatively accurate calculation results. In general, the flame radiation models described in the existing literature are all flame radiation models aiming at the thermal feedback of a certain intensity of the flame to the surrounding flame, and there is no complete research on the problem of the radiant heat feedback of the flame to the bottom of the flame.

\section{Reverse Heat Transfer Model}

In this study, we need to make the following assumptions about the flame: 1) the combustion reaction of combustibles belongs to the applied stoichiometric reaction; 2) the flame shape is roughly cylindrical; 3) the flame is equivalent and uniform, with symmetry; 4) radiant heat is evenly distributed in the flame body. To establish a flame model that superimposes the thermal radiation of each layer of flame on the steel plate (the diameter of the combustible material attached to the steel plate is longer than $0.2 \mathrm{~m}$, and the flame radiation feedback is the dominant thermal feedback mode), it is necessary to first determine the average height of the flame and layer the flame on this basis. Reasonable number of layers and height can improve the calculation accuracy [1] [2]. Equation (1) for the calculation of flame height in open space proposed by Heskestad [20]:

$$
H / D=3.7 Q^{2 / 5}-1.02
$$

where $H$ is the average flame height; $D=\sqrt{4 A / \pi}$ is the flame equivalent diameter; $A$ is the burn area; $Q$ is heat release rate.

The more layers there are, the more accurate the calculation results will be, and the accuracy assigned to the 20th layer is about $4 \%$ [18]. The temperature between each layer of flame is different, and the radiative heat feedback to the 
steel surface is also different. The calculation formula of radiation feedback [21] [22] [23] can be expressed by Equation (2):

$$
Q_{\text {rad }}=A \sigma\left(T_{f}^{4}-T_{0}^{4}\right)\left[1-\exp \left(-k l_{m}\right)\right]
$$

where $A$ is the burning area; $\sigma=5.67 \times 10^{-8}$ is the boltzmann constant; $T_{f}$ and $T_{0}$ are respectively the flame temperature and the initial temperature of the steel surface $20^{\circ} \mathrm{C} ; K$ is the effective absorption emission coefficient; $l_{\mathrm{m}}$ is the average beam length; $Q_{\text {rad }}$ is radiant heat feedback.

We can get the average beam length according to Equation (3) [22]:

$$
l_{\mathrm{m}}=3.6\left(A_{v}\right) / A_{\mathrm{s}}
$$

where $l_{\mathrm{m}}$ is the average beam length, $A_{v}$ and $A_{s}$ are the volume and surface area of each layer.

The effective absorption-emission coefficient $k$ can be determined by the following Equation (4) [24]:

$$
k=3.72\left(C_{0} / C_{2}\right) f_{v} T_{f}
$$

where $C_{2}$ is Planck's second constant $1.4388 \times 10^{-2} \mathrm{mK} ; f_{V}$ is the volume fraction of carbon black, usually $10^{-6} . T_{f}$ is the flame temperature; $C_{0}$ is a constant between 2 and 6 , depending on the complex refractive index $(m=n-k i$, where the real part $n$ is the refractive index of the absorbent medium, and the imaginary part $k$ is the absorption coefficient, which is determined by the attenuation of light as it travels through the absorbent medium).

For the semi-empirical prediction model, there is still an error between it and the real fire data, which is because factors such as ventilation condition, flame shape and space distance will have a great influence on the difference of Angle coefficient, thus affecting the accuracy of the model [25]. For the model of radiative feedback from upper flame to lower steel surface, the influence of Angle coefficient and atmospheric transmittance on the model is greatly reduced. Equations (3) and (4) are substituted into Equation (1) to obtain the radiant heat feedback of a certain layer of flame on the steel surface, and then the total radiant heat feedback after the superposition of the radiant heat feedback of each layer is Equation (5):

$$
Q=\sum Q_{\text {rad }}
$$

In summary, the volume and surface area of each layer of flame need to be quantified accurately to obtain a more accurate calculation result. Using digital image analysis technology to analyze the flame is a relatively effective means. The literature [26] [27] [28], a camera was used to take the flame image for digital image analysis, so as to obtain the geometric shape of the flame, but this requires better equipment and experimental conditions.

\section{Conclusions}

In this paper, the new problems caused by the burning accident of the thermal insulation material attached to the steel structure in recent years are considered, 
and the reverse heat conduction behavior of the combustible material attached to the steel structure is studied. The main conclusions are as follows:

In order to facilitate the study, according to the existing literature, the combustion of steel-attached combustible material is defined as the combustion reaction that occurs when the steel-attached combustible material (diameter longer than $0.2 \mathrm{~m}$ ) burns, which is the pool fire dominated by radiation feedback.

In the still air of an open area, the combustible material attached to the steel burns and emits a lot of heat to the outside world, compared with a small amount of heat into the steel structure. In this paper, a mathematical model is developed to quantify the radiant heat feedback into the steel structure.

\section{Acknowledgements}

The authors declare no conflicts of interest regarding the publication of this paper.

\section{Conflicts of Interest}

The author declares no conflicts of interest regarding the publication of this paper.

\section{References}

[1] Wang, X.-Z., Fan, Y.-Q., Zhou, K.-B. and Yu, Y. (2018) Multi-Layer Cylindrical Flame Model for Predicting Radiant Heat Flux from Pool Fire. Procedia Engineering, 211, 768-777. https://doi.org/10.1016/j.proeng.2017.12.074

[2] Zhou, K.B. and Wang, X.Z. (2019) Thermal Radiation Modelling of Pool Fire with Consideration on the Nonuniform Temperature in Flame Volume. International Journal of Thermal Sciences, 138, 12-23.

https://doi.org/10.1016/j.ijthermalsci.2018.12.033

[3] Mudan, K.S. (1984) Thermal Radiation Hazards from Hydrocarbon Pool Fires. Progress in Energy and Combustion Science, 10, 59.

https://doi.org/10.1016/0360-1285(84)90119-9

[4] Rogers, F.E. and Ohlemiller, T.J. (1981) Pyrolysis Kinetics of a Polyurethane Foam by Thermogravimetry; A General Kinetic Method. Journal of Macromolecular Science Chemistry, 15, 169-185. https://doi.org/10.1080/00222338108066438

[5] Lefebvre, J., Le, B.M., Bastin, B., et al. (2003) Flexible Polyurethane Foams: Flammability. Journal of Fire Sciences, 21, 343-367.

https://doi.org/10.1177/0734904103035369

[6] Hou, Y., Cheng, X., Liu, S., et al. (2015) Experimental Study on Upward Flame Spread of Exterior Wall Thermal Insulation Materials. Energy Procedia, 66, 161-164. https://doi.org/10.1016/j.egypro.2015.02.085

[7] Ma, X., Ran, T. and Fang, T.Y. (2018) Thermal and Fire Risk Analysis of Low Pressure on Building Energy Conservation Material Flexible Polyurethane with Various Inclined Facade Constructions. Construction and Building Materials, 167, 449-456. https://doi.org/10.1016/j.conbuildmat.2018.02.027

[8] Ma, X., Ran, T. and Xie, Q.Y. (2015) Experimental Study on the Burning Behaviors of Three Typical Thermoplastic Materials Liquid Pool Fire with Different Mass 
Feeding Rates. Journal of Thermal Analysis and Calorimetry, 123, 329-337. https://doi.org/10.1007/s10973-015-4898-0

[9] Ma, X. (2015) Study on Downward Flame Spread Behavior of Flexible Polyurethane Board in External Heat Flux. Journal of Thermoplastic Composite Materials, 28, 1693-1707. https://doi.org/10.1177/0892705715569826

[10] Tu, R., Zeng, Y., Fang, J. and Zhang, Y.M. (2016) The Influence of Low Air Pressure on Horizontal Flame Spread over Flexible Polyurethane Foam and Correlative Smoke Productions. Applied Thermal Engineering, 94, 133-140. https://doi.org/10.1016/j.applthermaleng.2015.10.108

[11] Ma, X., Tu, R. and Xie, Q.Y. (2015) Study on Downward Flame Spread Behavior of Flexible Polyurethane Board in External Heat Flux. Journal of Thermoplastic Composite Materials, 28, 1693-1707. https://doi.org/10.1177/0892705715569826

[12] Ma, X., et al. (2018) Experimental Study on Thermal Safety Analysis of Flexible Polyurethane at Various Facade Inclined Structures under Low Ambient Pressure Condition. Engineering Structures, 176, 11-19. https://doi.org/10.1016/j.engstruct.2018.08.106

[13] Ma, X., Tu, R., Ding, C., Zeng, Y., Wang, Y. and Fang, T.Y. (2018) Thermal and Fire Risk Analysis of Low Pressure on Building Energy Conservation Material Flexible Polyurethane with Various Inclined Facade Constructions. Construction and Building Materials, 167, 449-456. https://doi.org/10.1016/j.conbuildmat.2018.02.027

[14] Blinov, V.I. and Khudyakov, G.N. (1961) Diffusion Burning of Liquids, Army Engineer Research and Development Labs Fort Belvoir VA.

[15] Hottel, H.C. (1959) Certain Laws Governing the Diffusive Burning of Liquids: A Review. Fire Research Abstracts and Reviews, 1, 41-44.

[16] Hu, C., Zhu, G.Q., Wu, W.H. and Shen, Y.Z. (2011) Calculation and Analysis of Pool Fire Hazard Model. Fire Science and Technology, 30, 570-573.

[17] Li, Y. and Kang, Q.C. (2011) Application of Improved Point Source Method in Fire Radiation Calculation. Journal of China University of Petroleum, 35, 140-143.

[18] Zhou, K.B., Jiang, J.C. and Zhang, X. (2016) Flame Pulsation-Based Model for Predicting Radiant Heat Flux of Pool Fire. Journal of Nanjing Tech University (Natural Science Edition), 38, 114-118.

[19] Shen, J.-G., Ji, J.-W. and Wang, Z.-Y. (2017) Thermal Radiation Calculation of Conical Flame. Fire Science and Technology, 36, 1348-1351.

[20] Heskestad, G. (1995) Fire Plumes, SFPE Handbook of Fire Protection Engineering. 2nd Edition, National Fire Protection Association, Quincy.

[21] Ditch, B., de Ris, J., Blanchat, T., Chaos, M., Bill Jr., R. and Dorofeev, S. (2013) Pool Fires: An Empirical Correlation. Combustion and Flame, 160, 2964-2974. https://doi.org/10.1016/j.combustflame.2013.06.020

[22] Karatas, A., Intasopa, G. and Gülder, Ö. (2013) Sooting Behaviour of n-Heptane Laminar Diffusion Flames at High Pressures. Combustion and Flame, 160, 1650-1656. https://doi.org/10.1016/j.combustflame.2013.03.008

[23] Drysdale, D. (2011) An Introduction to Fire Dynamics. 3nd Edition, John Wiley \& Sons, Ltd., New York. https://doi.org/10.1002/9781119975465

[24] Fang, J., Wang, J.W., Tu, R., Shang, R., Zhang, Y.-M. and Wang, J.-J. (2018) Optical Thickness of Emissivity for Pool Fire Radiation. International Journal of Thermal Sciences, 124, 338-343. https://doi.org/10.1016/j.ijthermalsci.2017.10.023

[25] Shi, C.L., Liu, W., Hong, W.J., Zhong, M.H. and Zhang, X.K. (2019) A Modified Thermal Radiation Model with Multiple Factors for Investigating Temperature Rise 
around Pool Fire. Journal of Hazardous Materials, 379, Article ID: 120801. https://doi.org/10.1016/j.jhazmat.2019.120801

[26] Zhang, X.L., Hu, L.H., Wu, L. and Kostiuk, L.W. (2019) Flame Radiation Emission from Pool Fires under the Influence of Cross Airflow and Ambient Pressure. Combustion and Flame, 202, 243-251.

https://doi.org/10.1016/j.combustflame.2019.01.015

[27] Li, Y.T., et al. (2014) Large-Scale Experimental Study on the Spread and Burning Behavior of Continuous Liquid Fuel Spill Fires on Water. Journal of Fire Sciences, 32, 391-405. https://doi.org/10.1177/0734904114526956

[28] Li, Y.T., Xu, D.D., Huang, H., Zhao, J.L. and Shuai, J. (2020) An Experimental Study on the Burning Rate of a Continuously Released n-Heptane Spill Fire on an Open Water Surface. Journal of Loss Prevention in the Process Industries, 63, Article ID: 104033. https://doi.org/10.1016/j.jlp.2019.104033 